\title{
Cancer Epidemiology
}

National Cancer Institute

\section{Source}

National Cancer Institute. Cancer Epidemiology. NCI Thesaurus. Code C18668.

Cancer epidemiology involves the study of how physical surroundings, occupational

hazards and personal habits (smoking, diet and lifestyle) may contribute to the development of cancer. 